\title{
PLANIFICACIÓN TERRITORIAL FRONÉTICA Y ÉTICA PRÁCTICA. ACORTANDO LAS DISTANCIAS ENTRE PLAN Y PODER (POLÍTICA) ${ }^{\mathrm{i}}$
}

\author{
JOAQUín FARINÓS DASÍ ${ }^{1}$ \\ Olalla Vera Pastor ${ }^{1}$
}

\begin{abstract}
RESUMEN - La capacidad de planificar deriva de la voluntad de los planificadores y de su conceptualización del territorio, además de otros elementos del "entorno de decisión". Algunos autores han puesto el acento en la "cultura de la planificación" (la vieja discusión sobre lo ideal -normativo - y lo posible - real - en la teoría de la planificación), pero esta vez como determinante de la "planificación de la conducta", de la acción desde los tomadores de decisiones. Más específicamente identifican las “características del ambiente de decisión”: la estructura formal-legal, la estructura informal y las características del sistema de gobierno. Así, la planificación del territorio deriva del resultado del juego democrático (accountability, responsability y sustainability) entre los poderes presentes en el territorio. Por tanto debemos poner en relación la cultura de planificación como ethos colectivo, y las actitudes de los planificadores, con la propia función del Estado. El objetivo: facilitar una fluida relación entre gobierno, buen gobierno, gobernanza y gobernabilidad efectiva de los territorios. En el texto se pretende abordar esta circunstancia y orientar al lector para comprender y mejorar este proceso. Se recupera para ello el valor de la phronesis aristotélica, adaptada al contexto actual. En su primer apartado se presenta el cambio que en materia de planificación supone la teoría de la racionalidad deliberativa, y sus límites. En el segundo, tomando a Foucault como referencia, se introducen las relaciones de poder como crítica y respuesta a los planteamientos de Habermas. En el tercero se propone la frónesis como opción que aúne ambos planteamientos y sirva de base para una nueva planificación y gestión territorial, mediante una mejor consideración del territorio en la agenda política. Se concluye que se ha venido avanzando especialmente en la investigación en planificación fronética, una parte de la ecuación, pero no tanto en la más importante frónesis de la política (tomadores de decisiones). Ello reclama una reorientación del foco de atención que pase del estudio de los instrumentos y marco legal de la planificación territorial, al de los procesos mediante los que se toman las decisiones, al de los sistemas de evaluación y seguimiento (de impacto territo-
\end{abstract}

1 Dpto. de Geografía e IIDL de la Universitat de València. E-mail: joaquin.farinos@uv.es; olallavera@gmail.com 
rial), pero sobre todo al de la forma en que promover una nueva cultura territorial más vigilante ('areté' aristotélica). Muchas de las innovaciones y pretendidos avances encuentran sus problemas no tanto en la definición de nuevos marcos legales e instrumentales sino en el hecho de que la población no los llega a comprender y, lo que es peor, no los comparte.

Palabras clave: Planificación fronética; política territorial; ciencia posnormal; transdisciplinariedad; path dependence.

RESUMO - Planeamento territorial “Fronético” y ética práctica. EnCURTANDO AS DistÂNCIAS ENTRE PLANO E PODER (Política). A capacidade de planear resulta da vontade dos planeadores e da sua conceptualização do território e de outros elementos do "ambiente de decisão". Alguns autores têm colocado ênfase na "cultura de planeamento" (o velho argumento sobre o ideal - normativo - e o possível - real - na teoria do planeamento), mas como determinante do "planeamento da conduta", da acção dos decisores. Mais especificamente identificam as "características do ambiente de decisão": estrutura formal-legal, estrutura informal e características do sistema de governo. Assim, o ordenamento do território deriva do resultado do jogo democrático (accountability, responsibility, sustainability) entre os poderes presentes no território. Portanto, devemos relacionar a cultura de planeamento com o ethos coletivo e as atitudes dos planeadores com a própria função do Estado. O objetivo: facilitar um bom relacionamento entre o governo, boa governação, governança e governabilidade efetiva dos territórios. O texto aborda esta circunstância e procura orientar o leitor para compreender e melhorar este processo. Recupera-se o valor da phronesis aristotélica, adaptada ao contexto actual. Na primeira secção é apresentada a mudança no planeamento que envolve a teoria da racionalidade deliberativa e seus limites. Na segunda, tendo Foucault como referência são introduzidas as relações de poder enquanto crítica e resposta às abordagens de Habermas. Na terceira propõe-se a phronesis como uma opção que combina as duas abordagens e forma a base para um novo planeamento e gestão territorial, através de uma melhor consideração do território na agenda política. Conclui-se que se tem progredido especialmente na investigação sobre o planeamento "fronético", uma parte da equação, mas não na mais importante phronesis da política (decisores). Isto exige uma mudança de enfoque que ultrapasse o estudo de instrumentos e enquadramento jurídico do ordenamento do território para o processo pelo qual as decisões são tomadas, o sistema de avaliação e monitorização (impacto territorial), mas especialmente em como promover uma nova cultura territorial mais vigilante ('areté' aristotélica). Muitas das inovações e pretensos desenvolvimentos encontram problemas não tanto na definição de novos enquadramentos legais e instrumentos, mas no fato de que as pessoas não os compreendem e, o que é pior, não os partilha.

Palavras-chave: Planeamento "fronético"; política territorial; ciência pós-normal; transdisciplinaridade; path dependence.

ABSTRACT - Territorial PlanNing phronetics AND ETHiCAl Practice. BridGING THE GAP BETWEEN PLAN AND POWER (POLICY). Plan capacity derives from the will of planners and their conceptualization of the territory, as well as other elements of the "decision environment". Some authors have emphasized the "planning culture" (the old discussion on the ideal - normative - and possible - real - on the theory of planning), but as a determinant of "conduct planning", that is, the action of decision makers. More specifically identifying the "environment decision conditions": formal-legal structure, the informal 
structure and the characteristics of the system of government. Thus, spatial planning derives from the outcome of the democratic game (accountability, responsibility and sustainability) between the powers on the ground. We must therefore relate the culture of planning as a collective ethos, and the attitudes of planners, with the State's own role. The goal is to: facilitate a fluid relationship between government, good governance, governance and effective governance of the territories. The paper seeks to address this issue and to provide the reader with orientations to understand and improve this process. It recovers the value of the Aristotelian phronesis, adapted to the current context. The first section deals with the changes that deliberative rationality, and its limits, represent to planning theory. In the second section, taking Foucault as a reference, power relations as criticism and response to Habermas' approaches are introduced. The third proposes the phronesis as an option that combines both approaches, and serves as a basis for new planning and territorial management, through a better consideration of the territory on the political agenda. It is concluded that progress has been made especially in Phronetic Planning Research, a part of the equation, but not so much in the most important part, that of phronetic politics (decision makers). This calls for a reorientation of the focus from the study of instruments and the legal framework for territorial planning, to the processes by which decisions are made, to the systems of monitoring and evaluation (of territorial impact), but above all to the way that they promote a new more vigilant territorial culture (Aristotelian 'areté'). The problem with many of the innovations and supposed advances is not so much in the definition of new legal and instrumental frameworks but with the fact that the population does not understand them and, worse, does not share them.

Keywords: Phronetic planning; spatial policy; territorial politics; posnormal science; transdisciplinarity; path dependence.

RESUME - AMÉNAGEMENT TERRITORIAL « FRONETIQUE » ET ÉTHIQUE PRATIQUE. EN RACCOURCissant Les distances entre plan et pouvoir (politique) - La capacité d’aménager résulte de la volonté des aménageurs, de leur conceptualisation du territoire et d'éléments de l' "environment de décisions». Plusieurs auteurs ont souligné l'influence de la "culture de l'aménagement", c'est à dire du vieil argument entre l'idéal - normatif - et le possible - réel - sur l'action des décideurs. L'objectif du présent texte est, d'une part, d'orienter le lecteur dans la compréhension des rapports entre la "culture de l'aménagement" et le ethos collectif et, d'autre part, de contribuer à l'amélioration des relations entre le gouvernement, la bonne gouvernance et la gouvernabilité effective des territoires. On récupère la valeur de la phronesis aristotélique, adaptée au contexte actuel. On commence par présenter le changement de l’aménagement qui prend en compte la théorie délibérative et ses limites (Section 1). Ensuite, en ayant Foucault comme référence, on introduit les relations de pouvoir en tant que critique et réponse à l'approche de Habermas (Section 2). Dans la section 3, on propose la phronesis comme une option qui combine les deux approches et sert de base à de nouveaux aménagements et à la gestion du territoire, grâce à une plus efficace considération du territoire dans l'agenda politique. Pour conclure, on constate des progrès sur la recherche de l'aménagement "fronétique" (ce qui ne constitue qu'une partie du problème), mais pas beaucoup d'améliorations en relation à la plus importante phronesis de la politique (décideurs), qui exigerait un changement d'approche. Celle-ci devrait dépasser l'étude des instruments et du cadre juridique de l'aménagement du territoire pour tenir compte des processus à travers 
lesquels les décisions sont prises, du système dévaluation et de contrôle (impact territorial) et surtout de la promotion d'une culture territoriale plus vigilante ('areté' aristotélique). Beaucoup d'innovations et de soi-disant développements sont difficiles à appliquer, non pas en raison de problèmes de définition de nouveaux cadres légaux et d'instruments, mais parce que les gens ne les comprennent pas et, pire, ne les partagent pas.

Mots clés: Planification "fronétique"; politique territoriale; science post-normale; transdisciplinarité; path dependence.

\section{LA PROPUESTA DE LA RACIONALIDAD DELIBERATIVA DE HABERMAS COMO SOPORTE DE UNA RENOVADA PLANIFICACIÓN COLABORATIVA: DESEOS Y LÍMITES. A MODO DE INTRODUCCIÓN}

La comprensión de la tensión entre lo normativo y lo real, entre lo que se debe hacer y lo que se hace en realidad, es un elemento clave para poder entender la dialéctica de la planificación/gestión (implementación) y también de la democracia moderna y las conflictivas relaciones entre ciudadanía y gobierno (Farinós, 2014a). La planificación y la democracia aparecen como secuestradas (Farinós, 2015a), una por la racionalidad comprehensiva, otra por los procedimientos de regulación, y ambas por la tecnocracia. Por ello, para su recuperación, resultan condiciones clave una reforzada cultura territorial con mayor participación y una nueva planificación estratégica (evaluable y bajo la visión crítica de la ciudadanía). Robustecer la democracia a través del fortalecimiento de la sociedad civil. Las agrupaciones de la sociedad civil son las que se ocupan de mantener y redefinir los límites entre esta y el Estado a través de dos procesos interdependientes y simultáneos: por un lado la expansión de la igualdad social y la libertad, y por otro la reestructuración y la democratización de las instituciones de aquel (Keane 1988: 14; Flyvbjerg, 1998). Cabe plantearse si este empoderamiento se produce en términos de consenso o si, por el contrario, de conflicto; sin olvidar que la desigualdad y la dominación son dos elementos que se han integrado en el concepto de sociedad civil desde el inicio (Keane, 1988: 21).

Esta situación abre de nuevo algunos interrogantes como el de la racionalidad subyacente (si alguna) que deba motivar las decisiones (basadas en evidencias, y cuáles); si es posible, o no, mantener, algunos de los principios de la planificación racional comprehensiva del técnico, que hacen de ella una labor científica que otorga 'seguridades' a los tomadores de decisiones. La respuesta es distinta para el caso de los problemas de tipo estructurado (con una única solución mejor posible) que para los desestructurados (y el futuro deseado para un territorio y su comunidad lo es). Con todo, debe evitarse tanto el relativismo y nihilismo como el dogma, la arbitrariedad con el método.

Desde la teoría de la planificación (vid. Benabent, 2014) podemos acercarnos a algunas cuestiones clave en la relación experto-decisor-ciudadano. La primigenia planificación del Plan Director como obra de autor, no democrático sino más bien 'despótico ilustrado', se fundamentaba en la confianza y en la certidumbre de que éste se iba a cumplir 
según era diseñado. Se presuponía entonces que los objetivos sociales eran estables, existía consenso social sobre ellos y que los profesionales eran capaces de reconocerlos y formular respuestas eficientes. El plan era todo menos flexible; comprehensivo y a largo plazo. La crítica a ser dependiente de la 'inspiración', del arte creativo del experto, es lo que lleva, como reacción, a la emergencia y consolidación de la planificación racional comprehensiva con unos planteamientos positivistas, nomotéticos, que todavía permanecen por la indiscutible bondad de algunos de sus trazos. Uno de los elementos principales de este cambio que nos interesa destacar en este texto es que trata de distinguir claramente los hechos (lo importante) de los valores a la hora de plantear alternativas y tomar decisiones. La planificación pasa de verse como arte a ciencia. El planificador, a quien en una nítida segmentación de roles corresponde plantear soluciones a los fines/problemas que le propone el político (de acuerdo con sus normas y valores básicos; lo que en su caso no importa y se da por asumido), debe actuar de forma aséptica, imparcial y libre de valores y prejuicios. La decisión solo debería ser aceptada si se demuestra superior a su alternativa, medida respecto de uno o más criterios relevantes para el objetivo perseguido (de acuerdo con los pertinentes estándares de consistencia y lógica). De esta forma se establecen unas bases objetivas ('inequívocas') para el acuerdo o la gestión del conflicto.

Se parte del presupuesto de Geddes de que la labor del técnico termina con la formulación del plan, sin entrar en la elección del problema, al principio, ni en la gestión del mismo, una vez resulta formulado. Algo que no comparten desde antaño autores como McLoughlin (1969) para quien muchas veces el político no sabe o no puede definir bien los fines, situando al técnico de igual a igual con el político en esta función; o Chadwick, 1971, que incluso ve la técnica por encima del debate político a la hora de determinar los objetivos (recuperando la prelación del experto del anterior paradigma). Faludi (1973) presenta una interpretación más conciliadora, aunque separando ambos roles, al argumentar que el grado de libertad de los decisores para determinar los fines se encuentra constreñido (agenda heredada, marco legal, presupuestos...) y el técnico debe ayudar a encontrar las mejores soluciones dentro de las limitaciones existentes. Desde este punto de vista los medios no derivan de los fines, sino que la planificación es cíclica, existiendo un intercambio entre ambos, lo que nos introduce de lleno en los presupuestos de la llamada ciencia posnormal y, también, entonces, a la discusión sobre las posibilidades de 'racionalidad' pura, únicamente posible en condiciones de certeza, y la emergencia del nuevo paradigma de la racionalidad limitada. Esto nos lleva de la decisión 'perfecta' (homo economicus) a la decisión 'satisfactoria' (March \& Simon, 1958), razonable de entre las posibles (más de una, por tanto con enfoque de 'problema desestructurado') del hombre 'administrativo' (Simon, 1945).

Una de las cuestiones clave que debemos considerar en el actual contexto es la de cómo gestionar el tránsito, y cohabitación, de la diferencia entre hechos y valores, desde la planificación racional comprehensiva (donde los primeros deben supeditar a los segundos) a la que existe entre valores e intereses del hombre administrativo y de la política (y en esta nueva relación los segundos hacen tambalear los primeros, limitando las garantías - técnicas, útiles y democráticas - de una decisión). En este artículo nos acercamos a 
algunas reflexiones que tienen su origen en el campo de la filosofía, basándonos en la ética discursiva de Habermas y la analítica de poder de Foucault.

En el texto se recupera el principio aristotélico de Phronesis, al objeto de poder encontrar los fundamentos que permitan aproximarse a un punto justo de equilibrio entre lo necesario (lo moral o éticamente necesario, lo que se debe hacer, o lo que se planifica "racionalmente") y lo posible (lo que de hecho puede hacerse dada la verdadera correlación de poderes y el alcance real del Estado de Derecho y el nivel de gobernabilidad real); entre lo axiomático de racionalidad perfecta y el relativismo (contextualización y path dependence como opción), para pasar de la retórica a los efectos reales, mejorando las relaciones entre planificación-gestión y entre académicos-técnicos-tomadores de decisiones. Solo así la planificación y la gobernanza son posibles y tienen sentido.

La planificación tiene algún sentido si la gobernanza no se reduce a una simple negociación de la diversidad de intereses presentes en el territorio, contrapuestos en la mayoría de ocasiones. No se podría hablar de gobernanza, sino simplemente de la ley del más fuerte, si no se pretendiera obtener una visión más clara y decidida del futuro, cuyo fin último es mejorar las condiciones de vida de la ciudadanía.

Tomando a Kant como punto de partida, Habermas es el filósofo de la Moralität (Moralidad) basada en el consenso. Foucault, siguiendo a Nietzsche, es el filósofo de la Wirkliche Historie (Historia Real), en términos de conflicto y poder. Kant intentó desarrollar una Racional Universal (sin conseguirlo, dado que se basó en la pretendida racionalidad perfecta del sujeto). No obstante, este mismo principio sirve de base para las instituciones democráticas que contempla Habermas. Sin una filosofía universal constituida, la ciencia y la democracia, señala Habermas, serían producto del contextualismo, del relativismo y del nihilismo, lo que considera peligroso. Lograr la codiciada fundamentación racional y universal para las instituciones sociales no ha sido tarea fácil, y en ello también fracasaron Hegel, Marx (al centrarse en la subjetividad del sujeto, la filosofía del sujeto - Habermas, 1987: 294 -, como individuo o como clase obrera) y otros pensadores contemporáneos. Así y por tanto, el autor propone pasar del enfoque de la subjetividad al de intersubjetividad, y del enfoque del individuo al de comunidad (racionalidad comunicativa). El objeto de la racionalidad comunicativa es la unificación a partir de la coordinación de la acción, y la "universalización" como el principio de la ética discursiva. En una sociedad adaptada a este modelo, la ciudadanía se define en términos de participación en el debate público.

El modelo de participación sugerido es el de la participación discursiva. La participación toma significado en la medida en que es posible la racionalidad comunicativa, y para ello se establecen cinco requisitos (idealmente); más un sexto que sería el tiempo limitado (Habermas, 1993: 31; 1990: 65-6; Kettner, 1993):

1. Ninguna de las partes que intervienen deben ser excluidas del discurso (requisito de generalidad). El autor pone el acento en el concepto de participación inclusiva, dando voz especialmente a quienes más dificultades tienen para hacerse oír.

2. Todos los participantes deben tener la misma posibilidad de presentar y criticar las pretensiones de validez en el proceso del discurso (requisito de autonomía). 
3. Los participantes deben estar dispuestos y ser capaces de empatizar con las pretensiones de validez de cada uno (requisito de empatía).

4. Las diferencias de poder existentes entre los participantes deben ser neutralizadas, para que no tengan ningún efecto en la creación de consenso (principio de igualdad).

5. Los participantes deben explicar abiertamente sus objetivos e intenciones (principio de lealtad y transparencia).

Todos los interesados, en principio, participarían así, libremente y por igual, en una búsqueda cooperativa de la verdad, donde nada coacciona a nadie, excepto a través de la fuerza del mejor argumento. La validez se define como consenso sin fuerza, porque una norma no consensuada no obtiene el consentimiento de los participantes; del mismo modo que todos los afectados pueden aceptar libremente las consecuencias de una norma controvertida (Habermas, 1990: 93). La universalidad deriva del hecho de que para Habermas la vida social humana está sobre la base de los procesos para el establecimiento de la comprensión recíproca. Estos procesos se presuponen "universales porque son inevitables". Como consecuencia, los seres humanos se definen como seres democráticos, como homo democraticus (Habermas, 1985: 196). Constituye la base epistemológica desde la que se abren paso las nuevas acciones de gobernanza democrática y de planificación estratégica, o de democracia y de planificación colaborativas, más flexibles y más atentas a los intereses presentes (bottom-up), y por tanto con menores barreras de entrada. De esta manera se otorgan mayores seguridades y certezas en la planificación territorial (Farinós, 2009; Farinós, 2015b).

La ética del discurso de Habermas no se debe confundir con tipos contingentes de negociación ni con modelos de compromisos negociados estratégicamente entre conflictos de intereses particulares. La diferencia respecto a ellos está en el recurso a la justificación normativa, del mismo modo que sucede con un refinado entendimiento de la gobernanza. Para Jessop (2003), el interés en las nuevas formas de gobernanza reside en su supuesta capacidad para solucionar problemas de coordinación de un amplio rango de sistemas (económico, legal, político, de protección...) y de la propia sociedad civil. A diferencia del funcionamiento del mercado, en el que cada cual busca su propio interés, la ética del discurso de Habermas presenta una naturaleza comunitaria. Este mismo carácter público, de política pública, está presente en la definición de gobernana que realizan Ansell \& Gash (2008), quienes ponen el acento en la gobernanza colaborativa (participativa o democrática) (Farinós \& Ferrão, 2015).

Habermas es un universalista, moralista "de arriba a abajo": las reglas para el correcto proceso son normativamente dadas por adelantado, en forma de requisitos para establecer los ideales de la situación del habla. Por el contrario, en cuanto a contenido, Habermas es un situacionalista bottom-up: lo que es correcto y verdadero en un proceso de comunicación dado está determinado únicamente por los participantes. Habermas, en la ética del discurso y la racionalidad comunicativa, establece que "en el Discurso, la ética no establece orientaciones sustantivas. En lugar de ello, establece un procedimiento basado en presuposiciones y diseñado para garantizar la imparcialidad del proceso de juzgar" (Habermas, 1990: 122) ). $^{\mathrm{ii}}$. 
Para Habermas, corresponde al Estado fijar el marco normativo que facilite esta participación. Una importante cuestión que sin embargo no resuelve es hasta qué punto el hecho de facilitar el marco institucional supone que la población decida participar y lo haga adecuadamente (pongamos como ejemplo el caso de la Directiva Europea de Evaluación Ambiental Estratégica de planes y programas); algo que la nueva planificación local estratégica sí trata de facilitar, constituyéndose como un buen indicador de 'democracia' en tanto que proceso de co-producción de futuros con una naturaleza inherentemente política.

Como queda demostrado en la bibliografía (Albrechts, 2016), la capacidad de los sistemas de planificación territorial estratégica para poder ofrecer los resultados esperados no dependen únicamente del sistema legal y político sino también de las condiciones (sociales, culturales, del contexto) que subyacen al mismo. En este sentido, como dice el autor, la tarea de planificación no quedaría únicamente en ver qué tipo de acciones (alternativas) son las más deseables de acuerdo con los objetivos sino también, e incluso más importante, ver en qué cambios en la política y en el sistema serían necesarios o deseables para poder conseguirlos. El foco pasará de 'lo que debe ser' (el estado final) al modo en que puede conseguirse (acciones, cambios, movimiento, relaciones, conflictos, procesos... - Chia, 1995 y 1999); lo que acerca a las teorías del caos, al organicismo y a los sistemas complejos. Sin embargo, el estado final (el futuro deseado) acaba siendo resultado de un proceso de selección que incluye evaluaciones, juicios y decisiones que han ido conduciendo al cambio en la dirección deseada.

Volviento a Habermas, opera dentro de una perspectiva de derecho y de soberanía. Para lograr el fortalecimiento de la sociedad civil se precisa tanto de la redacción de las constituciones como del desarrollo de las instituciones. La autorización del poder por la ley y la sanción de la ley por el poder deben producirse recíprocamente. La soberanía es un requisito previo para la regulación del poder por la ley (una perspectiva que contrasta claramente con la de Foucault, 1980: 87-8, como veremos). Para Habermas lo que une a la ciudadanía de una forma social, cultural y filosófica (weltanschauliche) basadas en el pluralismo son, en primer lugar, los principios abstractos de un orden republicano artificial, creado por medio de la ley (no habría sociedad sin ley).

El problema, sin embargo, como ha señalado Putnam (1993: 17-8), es que "la experiencia de las constituciones escritas (en el mundo) nos advierte (...) que los diseñadores de nuevas instituciones a menudo las escriben sobre papel mojado (...) Que las reformas institucionales alteran la conducta es una hipótesis, no un axioma”. No resuelve, por tanto, el desencuentro entre el ideal y la realidad, entre las intenciones y la aplicación, entre lo que debiera ser y lo que es. Habermas describe la utopía de la racionalidad comunicativa, pero sus críticos le consideran idealista y le reprochan que no concrete cómo llegar a ella. Esta crítica adquiere relevancia sobre todo al carecer de un entendimiento concreto de las relaciones de poder, imprescindibles para promover cualquier tipo de cambio político, tal y como hemos comentado. No resulta una crítica nueva ni original, y cuenta con muchos antecedentes: Maquiavelo (a quien respondía Alejandro II de Prusia) $)^{\text {iii }}$, Nietzsche, Derrida o Foucault (para quien el poder siempre está presente - Fou- 
cault, 1988: 11) entre otros. La presencia de los intereses del poder en la comunicación (y su "validez") se manifiesta en la retórica no racional, en la elocuencia, en el control oculto, en el carisma, en la propaganda (lo que nos lleva al control de los medios de comunicación y, hoy en día, al oligopolio de los grandes grupos), en las relaciones de dependencia entre los participantes... con el consiguiente resultado de la "distorsión". La comunicación pasa de ser el instrumento perfecto para la búsqueda de consensos "éticos" a ser el medio para el ejercicio del poder y la retórica ${ }^{\text {iv }}$. ¿Puede la racionalidad entonces considerarse aislada del poder? La respuesta para los críticos de Habermas es que no.

Este argumento coincide con el propio Platón, quien ya decía que "se equivocan profundamente los hombres idealistas cuando ponen su esperanza de perfección en la política" (Platón, República VI, 496d). Eso debería explicar por qué los sabios se abstienen de los negocios públicos (Platón, República VI, 496d). Pero ¿y entonces? ¿No cabe otra que abrazar el "perded toda esperanza" del infierno de Dante en su "Divina Comedia"; o es posible "decir" desde los principios de la ética y la virtud (idealista, no ilusa), para poder hacer mejor (lealtad y transparencia, contrato social, programa-contrato y dación de cuentas frente a los códigos de silencio) en la(s) política(s) pública(s)? Dicho de otro modo, ¿nos circunscribimos a los juegos de poder (en un encorsetado game management y lejos de una verdadera gobernanza, ocupada de asuntos públicos de interés general - Farinós y Ferrão, 2015) o es posible liderar los procesos de forma no determinista? ¿Nos concentramos en la gestión olvidando la planificación, como parece ser la moda más reciente espoleada por el neoliberalismo y la actual crisis que parecen retroalimentarse mutuamente?

En un contexto como el actual en el que quiere imponerse la idea de que los problemas socio-territoriales tienen solución mediante la desregulación ('despolitizando' la economía) y el ajuste del libre mercado (un viejo argumento renacido con vigor al calor de la crisis que precisamente ha provocado, aprovechando, cual movimiento de judo, para acusar de 'viejas y pasadas de moda' las recetas de lucha contra esta situación, por 'anticapitalistas'), la planificación territorial debe enfrentarse a dos grandes tipos de retos, ontológicos y epistemológicos (Albrechts, 2016): cuál debe ser su alcance, enfoque, con qué herramientas, técnicas y habilidades, cómo considerar el contexto, con qué recursos, conocimiento de base y nivel (necesario) de involucración de (un amplio rango de) actores.

Entre los extremos de una norma ideal (pero irreal) y el relativismo o pragmatismo extremo y nihilismo (sin principios ni ética posible) es necesario encontrar una solución distinta... y útil. Respondemos a estas cuestiones en los apartados que siguen basándonos en los planteamientos de Foucault y con el principio aristotélico de phronesis.

\section{DEL “DEMOCRATICUS HOMO” AL CONFLICTO DE INTERESES Y EL PODER; ¿INTERÉS GENERAL?}

Si Habermas se basa en una adecuada cultura política y en el constitucionalismo patriótico como el medio principal para asegurar el cumplimiento de los principios constitucionales, la situación en la vida real es distinta. Como afirmaba Prats, no todo en la 
vida de los individuos es regulable (o la regulación tiene efectos; es necesario un código ético o deontológico propio en su lugar). Maquiavelo iba más lejos al afirmar que a la hora de legislar debe tenerse en cuenta que todos los hombres son malos y que actúan como tales en cuanto la oportunidad se les presenta (Maquiavelo, 1996). En otras palabras, la constitución de una sociedad democrática se puede doblar y utilizar de forma no democrática para uso personal o ventaja de algún grupo (Flyvbjerg, 1998b). Habermas se sitúa en un plano fuertemente normativo y procedimental y presta muy poca atención a las condiciones previas del discurso real. A diferencia de sus tipos ideales, existen los conflictos de interés, normativa y empíricamente, que comprometen la racionalidad comunicativa, y la convierten según sus críticos en un argumento vacío excesivamente formal, idealista y con falta de sensibilidad hacia el contexto. "El problema aquí es que en situaciones no triviales hay pocos criterios claros para la determinación de lo que se considera un argumento, lo bueno que es, y cómo diferentes argumentos deben ser evaluados unos contra los otros. Toda sociedad debe tener algunos procedimientos para hacer frente a los conflictos que no puedan ser resueltos por la argumentación - incluso cuando todas las partes se comprometen a la argumentación racional" (Bernstein, 1992: 220). Como solución a esta limitación, valga resaltar el papel de la evaluación (de políticas, planes, programas y/o proyectos) en sus distintas modalidades (Evaluación Ambiental Estratégica, Evaluación de Impacto Territorial, Evaluación de Impacto Ambiental...), para poder suministrar evidencias sobre las que poder basar la selección de alternativas y las decisiones finales de la política (supuestamente).

Muy alejadas de las primeras democracias liberales y del contrato social (de racionalidad formal), las democracias modernas (de racionalidad real) requieren de una mayor atención a las relaciones de poder como forma de poder lograr más democracia. Si el objetivo es avanzar hacia el ideal de Habermas, entonces la primera tarea es entender las realidades del poder. Para ello se trae a colación la obra de Michel Foucault, quien ha tratado de desarrollar dicha comprensión (Flyvbjerg, 1998a).

Foucault reniega de los ideales y entre el ¿qué debo hacer? kantiano o el ¿qué hacer? de Lenin se sitúa claramente en el segundo (equivaldría a primar la gestión sobre la planificación), aportando con ello una sofisticada comprensión de la Real politik (Flyvbjerg, Landman \& Schram, 2012).

Foucault, familiarizado con la obra de Habermas y la Escuela de Frankfurt, rechaza tanto el relativismo como el fundamentalismo, y los sustituye por la ética situacional; es decir, por el contexto (contextualismo, que cabe relacionar con la path dependence, las narrativas o story lines, el "carácter" de cada territorio...). El autor se distancia del fundamentalismo y la metafísica. En su opinión las normas no se pueden dar en base universal, independiente de las personas y del contexto: "La búsqueda de una forma de moralidad aceptable por todos en el sentido que todo el mundo tendría que someterse a ella, parece catastrófico" (Foucault, 1984a), por cuanto implicaría una uniformidad ética (como la de Marx, Rousseau o Habermas) y una moralidad que pondría en peligro a la sociedad civil (entendida como comunidad particular o local). Debe actuarse, pues, como si los universales no existieran; nada es fundamental. 
Con ello, transita del utópico interés general (uno) a los diversos intereses de cada comunidad ${ }^{v}$. El énfasis de Foucault sobre la marginalidad hace su pensamiento sensible a la diferencia, a la diversidad y a las políticas de identidad; en este sentido se acerca al posmodernismo y al place based approach.

Para Foucault, la base para la comprensión y la actuación es la actitud de los que comprenden y actúan, y ello no se basa en una moral idiosincrásica o en preferencias personales, sino en una visión del mundo común dependiente del contexto y de los intereses de un grupo de referencia (de ahí la importancia que toma la inteligencia y la información territorial, este grupo es muy consciente de que el resto de grupos tienen diversas visiones del mundo y de intereses, y no existe ningún principio general (incluyendo la "fuerza del mejor argumento") para que todas las diferencias se puedan resolver. Para Foucault, el contexto está condicionado social e históricamente, un baluarte eficaz contra el relativismo y el nihilismo, y esto constituye la mejor base para la acción.

En su opinión, ni siquiera los completos sistemas institucionales pueden garantizar la libertad, a pesar de que se establezcan con ese fin. La constitución escrita no sería vista como una forma efectiva de empoderar a la sociedad civil. El pensamiento de Foucault en lo referente a leyes, constituciones y democracia se centra más en cómo se pueden utilizar de manera igualitaria y no en establecer más constituciones e instituciones, como defendía Habermas ${ }^{\text {vi }}$. El problema no es tratar de disolver las relaciones de poder en la utopía de una comunicación perfectamente transparente (transparencia y dación de cuentas de acurrdo con el Libro Blanco de la gobernanza europea - CE, 2001), sino establecer las normas de Derecho, las técnicas de gestión, así como la ética, que redujeran los juegos de poder que dieran como resultado un mínimo de dominación.

La resistencia y la lucha, en contraste con el consenso, es para Foucault la base más sólida para la práctica de la libertad. Para Hirschman (1994) los conflictos sociales son los verdaderos pilares de la sociedad democrática. Si las sociedades que suprimen el conflicto acaban por ser opresivas, paralelamente las teorías sociales y políticas que los ignoran o marginan también lo son potencialmente. Esto nos lleva a la teoría de los conflictos y a las técnicas de mediación y negociación (en busca de ideales comunes), una nueva competencia clave para el planificador según las tendencias más recientes (en USA y Australia por ejemplo; vid. American Planning Association, 2015 y Planning Institute Australia, 2015) $)^{\text {vii }}$. Por el contrario, Habermas aboga por el recurso a la norma, a la judicialización del conflicto y a su resolución a través de los procesos judiciales por el poder establecido y no por el entendimiento mutuo o el acuerdo. Algo que no siempre es deseable ni garantiza buenos resultados (especialmente en materia de ordenación del territorio, urbanismo y medio ambiente - vid. Farinós, 2009).

Tanto Foucault como Habermas consideran crucial la regulación de las relaciones reales de dominación, pero mientras el segundo plantea los enfoques de la regulación desde una teoría universalista del discurso, el primero busca un entendimiento genealógico de las relaciones de poder reales en contextos específicos. Mientras que la orientación de Habermas es hacia la episteme, Foucault se orienta hacia la phronesis, principio del que nos ocuparemos en el siguiente epígrafe. Habermas enfatiza la macro-política de 
procedimiento (el equivalente a la teoría, la planificación); Foucault hace hincapié en la política micro-sustantiva (la práctica, la gestión). Los dos son pensadores "de abajo a arriba" en lo que se refiere al contenido de la política (el individuo, la agencia sobre la estructura), pero donde Habermas piensa en un "de arriba a abajo" en lo se refiere a la racionalidad procedimental (tecnocrática), Foucault es un pensador "de abajo a arriba" en lo relativo tanto al proceso como al contenido (Flyvbjerg, 1998a).

Frente a la concepción idealista de Habermas, Foucault facilita una comprensión materialista de la política real y la política racional, y cómo éstas podrían ser cambiadas en un contexto específico. El problema de Foucault es que dado que la comprensión y la acción tienen sus puntos de partida en lo particular y lo local, pueden llegar a pasarse por alto las condiciones más generalizadas en relación, por ejemplo, con las instituciones, las constituciones y las cuestiones estructurales. Desde el punto de vista de la planificación, esto se resuelve con la integración del diagnóstico interno con el externo, pero no se resuelve del todo en la práctica de una verdadera gobernanza multinivel (idea de la multiescalaridad, multiterritorialidad y fuzzy geometries/fuzzy planning). El consenso político no puede ejercerse de forma tal que neutralice las obligaciones, compromisos e intereses diversos de la sociedad y de los niveles de poder. Todo ello garantiza la existencia del conflicto y la consiguiente necesidad de tener que gestionarlo a la hora de tomar decisiones.

\section{PERSIGUIENDO ESPERANZAS: LA FRÓNESIS COMO PUNTO DE EQUILI- BRIO ENTRE LO QUE DEBE SER (PLANIFICACIÓN) Y LO QUE PUEDE SER (IMPLEMENTACIÓN)}

Para Aristóteles, la ciencia natural y la social deben ser abordadas de forma distinta, una de la otra. Por ello, planteaba y discutía las tres virtudes intelectuales: episteme, techne y phronesis. Según Flyvbjerg (2001), la colonización de las ciencias sociales por las naturales explicaría por qué en el caso de la techne (tecnología o técnica a día de hoy) esta carece de referencia alguna a la virtud intelectual (fuera de la racionalidad perfecta del especialista). Las ciencias sociales (a diferencia de las naturales que no pueden hacerlo) son más fuertes en su papel de phronesis, en tanto contribuyen al análisis, reflexión y discusión sobre los valores y los intereses, que es, como se viene argumentando, el requisito previo para la adecuada gestión de los conflictos y para el deseado desarrollo político, económico y cultural. Por este motivo, debe avanzarse desde la concepción aristotélica original de phronesis (frónesis) a otra que explícitamente incluya el poder.

En opinión de Subirats (2016), "Aristóteles relacionaba directamente frónesis con la ciencia política, relacionando el despliegue que significa pasar de los elementos particulares a los generales o a una perspectiva social amplia, mediante el ejercicio de las leyes (donde partiendo de unos valores, se propone un itinerario controlado de cambio, proceso que se supone que conducirá a "buenos" resultados, a partir de unas circunstancias previas determinadas), y también de la necesidad de la deliberación para tomar decisio- 
nes colectivas... Desde la aproximación que aquí tratamos de defender y argumentar, los aspectos particulares, los aspectos contextuales, serían esenciales. O dicho de otra manera, la perspectiva apuntada refuerza la significación de los ejemplos, la importancia de los casos"viii. Un principio básico de la investigación fronética es que los ejemplos prácticos son típicamente vehículos de comunicación más eficaces que los que se plantean en las discusiones de la teoría y la metodología (Flyvbjerg, 2002) ${ }^{\mathrm{ix}}$.

De acuerdo con Aristóteles, la Phronesis (literalmente sabiduría práctica, sentido común ${ }^{\mathrm{x}}$ o prudencia) es la actividad más importante, por encima del episteme y la techne, porque, mediante la misma, la racionalidad instrumental (técnica) se equilibra por el valor racional (episteme o saber científico). Se trata, en su opinión, de la virtud intelectual más importante "motivada... capaz de actuar con respecto a las cosas que son buenas y malas para el hombre", que toma en cuenta los valores y va más allá del conocimiento analítico, científico (episteme), y de la técnica (techne o know how). En síntesis, la phronesis es más importante porque es la virtud intelectual que permite organizar (coordinar) el empleo ético de la ciencia (episteme) y la tecnología disponible (techne), y resulta la actividad intelectual más relevante para la praxis, que no puede ser encapsulada por reglas universales (reduccionistas y aprioristas que someten la realidad al modelo), y que requieren de una interacción entre lo general y lo concreto (lo que también cabrá relacionar con la multi/inter-escalaridad y la integración de los diagnósticos interno y externo), de la deliberación (participación, gobernanza democrática, planificación colaborativa), del juicio y de la decisión (la 'mejor' alternativa - sobre esta cuestión volveremos más adelante en este mismo epígrafe).

Esta sabiduría práctica implica no solo juicios de apreciación en términos de valores (lo que debe ser de la ética) sino también una comprensión de las realidades políticas (el contexto, las condiciones de cada espacio, incluida la cultura política) y las relaciones de poder. Y todo ello como parte de un sistema integrado. La praxis siempre queda supeditada a juicio dependiente del contexto, a la ética situacional. El contexto (la geografía, dirían Massey \& Allen, 2004) importa en planificación. Concuerda esto con la máxima de Aristóteles de que en las cuestiones de la praxis se debe confiar más en la esfera pública de la ciencia (deliberativa, posnormal). La frónesis es la más importante (en relación a la episteme y techne) porque a través de ella se equilibran las dos racionalidades (Weber, 1978): la racionalidad instrumental (medio-racionalidad, hasta ahora predominante de acuerdo con el método racional comprehensivo) y la racionalidad de los valores (racionalidad sustantiva). Tanto para Aristóteles como para Weber, el equilibrio entre ambas resulta crucial. Lo mismo, y este es nuestro argumento, que lo resulta para una adecuada relación entre planificación y gestión (implementación o puesta en práctica), entre expertos/académicos (planners) y tomadores de decisiones (decision/policy-makers).

Los conflictos de poder, como se ha comentado, resultan elementos de estudio clave dentro de la investigación social y política. Flyvbjerg (2002) trata de poner en práctica (para el caso de la planificación urbana escandinava) la metodología que desarrolló para los estudios del poder (su phronetic planning research). Lo hace desde una parte de la phronesis, la del planificador, que, con ser importante y sobre la que más podemos traba- 
jar como intelectuales, expertos y practicioners, no resulta decisiva. Esta función parece estar reservada a la phronesis de los políticos y tomadores de decisiones. De ahí la necesidad de avanzar en el estudio de cómo poder lograrla, por influjo de la técnica o, finalmente, de la cultura territorial (valores) suficiente.

La "investigación en planificación fronética" sigue la tradición de los estudios sobre el poder desde Maquiavelo y Nietzsche hasta Foucault y Bourdieu; porque, si se quiere entender el poder, el punto de partida deben ser los pensadores del poder, no tanto los de la racionalidad comunicativa. Pero, ¿qué debemos entender por investigación en planificación fronética? Ésta, en opinión de su creador, puede resultar útil no como imperativo metodológico sino como forma de ofrecer posibles indicadores de dirección a partir del análisis de experiencias.

Pero volvamos al origen del concepto y a la relación episteme/techne/phronesis. El término epistémico hace referencia al conocimiento científico, un estado de mente capaz de demostrar lo que sabe; se asemeja a nuestro ideal de la ciencia moderna (hipotético-deductivo, de leyes generales, nomotéticas, propio de las ciencias naturales). Por su parte techne y phronesis se vinculan a otras dos funciones alternativas del trabajo intelectual. El objetivo de la techne es la aplicación de conocimientos técnicos y habilidades para resolver un problema concreto; resulta pragmático, variable y dependiente del contexto (lo que Foucault, 1984b, denomina "racionalidad práctica regida por un objetivo consciente"). Por su parte la frónesis ética se orienta a la acción a partir de una racionalidad basada en la ética y los valores (racionalidad-valor). Pues bien, la investigación en planificación fronética como techne sería un tipo de consultoría capaz de desarrollar una planificación "mejor" por medio de una racionalidad instrumental (métodos y técnicas que son conocidas e innovadas) $)^{\mathrm{xi}}$. En este caso "mejor" viene definido en términos de valores y objetivos que resulten de la negociación con todos los actores (Flyvbjerg, 2004). La validez del "mejor argumento" se basa en la interpretación y su comparación con otras interpretaciones e investigaciones, aceptada o rechazada por el conjunto de actores. A diferencia de la racionalidad analítica e instrumental, la racionalidad práctica de la frónesis se basa en la razón inter-subjetiva, donde los actores se relacionan e interactúan en contextos específicos de poder y diálogo (dia-logos, discusión o contacto abierto entre dos o más partes, que surge con el propósito de lograr un acuerdo).

Una de las principales tareas de la investigación en planificación fronética es proporcionar ejemplos concretos y narraciones detalladas de las formas en que operan el poder y los valores, sus efectos y beneficiarios/perdedores, y cómo podrían ser modificados para tener otras consecuencias/efectos/resultados. Así se explica, por ejemplo, por parte de Albrechts (2016) al hacer referencia a su experiencia en la preparación del Plan de Flandes (Albrechts, 1999a,b \& 2003a,b) y, en general y con una aproximación más radical, a la planificación estratégica (Albrechts \& Balducci, 2013). Desde este punto de vista los planificadores no serían simples mediadores o facilitadores sino que juegan un papel activo, intrínsecamente unidos en las relaciones de poder, del que pueden acabar convirtiéndose en correas de transmisión o como contrapeso de los intereses predominantes. 
Se trata por tanto de un proyecto analítico, no teórico ni metodológico. Se centra tanto en los actores como en la estructura (en este sentido podría relacionarse con los análisis MACTOR de la prospectiva a la hora de definir los escenarios de futuro), y sobre la relación entre ambos: los actores de la planificación y sus prácticas se analizan en relación con las estructuras de las organizaciones, las instituciones y las sociedades de las que forman parte, al tiempo que las estructuras se analizan en términos de cómo son interiorizadas por la agencia. De acuerdo con Bourdieu (1990) esta es la forma de escapar a la disyuntiva entre estructuralismo sin sujeto y fisolofía del sujeto. En este mismo sentido de tender puentes entre agencia y estructura, cabe situar la teoría de la estructuración de Giddens (1984), o el trabajo de Putnam (1993) sobre la planificación moderna y democrática en Italia (Galland, 2012).

La persona (el ciudadano, el planificador, el tomador de decisiones) que posee la sabiduría práctica (phronimos) tiene conocimientos de cómo manejar cada circunstancia particular (contextualización, fenomenología, caso...), que nunca puede ser equiparado al conocimiento de las verdades generales (que se plantean desde el episteme y que el experto también conoce). Por tanto, la frónesis resulta más una habilidad tácita para hacer la ética práctica que una especie de ciencia (al menos en el sentido de las ciencias naturales), resultando mucho más cercana a la posnormalidad, a la transdisciplinariedad y al enfoque de sistemas complejos, más típicos en las ciencias sociales (vid. Funkowicz \& Ravetz, 1991, 1993). Ello nos lleva a la nueva interpretación, no sólo de la teoría de la planificación (vid. Benabent, 2014), sino también:

- al papel y perfil del planificador (American Planning Association, 2015; Planning Institute Australia, 2014), que se acerca más a la figura del mediador y gestor de conflicto dentro del proceso de elaboración de planes de ordenación territorial (Farinós, 2014b; Prezioso, 2008); y también, en este proceso,

- al momento clave de tránsito de la etapa de análisis y diagnóstico (que resuelve fácilmente la episteme y la techne) a la de formulación y selección de alternativas, un proceso mucho más contextualizado, deliberativo, iterativo y 'creativo' que requiere de algo más (la frónesis como base de esa supuesta 'inspiración', 'intuición' o 'arte', que ahora se convierte en 'sentido común' y 'ética práctica'), tanto para ofrecer la 'mejor opción' como para que ésta resulte 'aplicable' (con las menores barreras de entrada y los mejores efectos en la práctica - como ya comentábamos al referirnos a planificación colaborativa en Farinós, 2009).

¿Y cómo llevar a cabo la investigación en planificación fronética que se propone? Asumiendo, según Flyvbjerg, tres precondiciones:

- renunciar al racionalismo típico (Dreifus \& Dreifus, 1991), transitando de la planificación racional omnicomprehensiva a la teoría del conocimiento/acción y al paradigma comunicativo/deliberativo (en términos de relaciones de poder en cada contexto);

- abordar los problemas que importan a los grupos en las comunidades locales, nacionales y globales en los que vivimos (en este sentido cabe proponer un enfoque de policy packages transversales, como vectores o ejes estratégicos, propios de cada 
contexto, para poder abordar los problemas, tendencias, dinámicas... territoriales presentes, que deben ser identificadas, conceptualizadas y operativizadas a efectos de poder ser definidas, medidas y abordadas por las políticas);

- comunicar los resultados de nuestra investigación a los conciudadanos y escuchar atenta y cuidadosamente sus comentarios (lo que nos acerca a la figura de los planes de participación pública, su naturaleza, funciones y efectos...).

El objetivo de la investigación en planificación fronética es clarificar valores, intereses y relaciones de poder en la planificación como base de una buena praxis. Para ello debe responderse a cuatro cuestiones (Flyvbjerg, 2004): (1) ¿a dónde nos dirigimos con la planificación?, (2) ¿quién gana y quién pierde y cuáles son los mecanismos de poder?, (3) ¿es el resultado el deseable?, (4) ¿qué deberímos hacer al respecto? Según sea la respuesta a estas cuestiones, los resultados de la planificación en la práctica varían.

Las preguntas 1, 3 y 4 son las aristotélicas clásicas; la segunda es la realmente nueva que introduce explícitamente las relaciones de poder en la concepción original de Phro$n e s i s^{x i i}$. La planificación de hecho se utiliza como instrumento de control de los grupos dominantes sobre otros grupos, logrando así las 'seguridades' deseadas y el mantenimiento del status quo. Las preguntas se hacen con la conciencia de que no hay un "nosotros" general y unificado en relación con el cual la pregunta pueda tener una respuesta final única. Los investigadores deben ser conscientes de que la planificación será más eficaz si se centran en los valores e intereses de grupos específicos en el contexto de un poder particular, logrando con ello que llegue a ser una actividad más importante y reconocida por los involucrados 'en' y afectados 'por' el planeamiento (lo que a su vez posibilita una mayor participación, compromiso y evaluación, en una especie de espiral ascendente o virtuosa).

¿Quién gana, y quién pierde? ¿A través de qué tipo de relaciones de poder? ¿Qué posibilidades están disponibles para el cambio las relaciones de poder existentes? ¿Es conveniente hacerlo? ¿Cuáles son las relaciones de poder entre los que hacen estas preguntas? La investigación en planificación fronética plantea estas preguntas con la intención de evitar el voluntarismo y el idealismo característico. Eso significa que el investigador fronético tiene que tomar decisiones acerca de dónde empezar y terminar la historia, lo que subrayar, etc. Una vez más este tipo de decisiones se toman sobre la base de la forma en que mejor contribuyen a responder a las cuatro preguntas para el planeamiento antes citadas.

Con todo, y suponiendo un avance sobre cómo hacer de la planificación y al planificador más útiles y menos voluntaristas, cabe recordar que sólo resulta una parte de lo que podríamos llamar "los factores de la ecuación fronética". Es cierto que afecta a expertos/ técnicos/científicos planificadores y alude o afecta, de paso, a ciudadanos, grupos de interés y tomadores decisiones/políticos. Y la gobernanza democrática y la democracia más participada (metafísicamente una contradicción en sí mismas, como hemos comentado a lo largo del texto y en trabajos precedentes) ponen el énfasis en el papel de la agencia, de la ciudanía y en un re-empoderamiento de la misma; también en la emergencia o en su caso mantenimiento (cuando exista -véase lo que está sucediendo desde principios del 
siglo XXI en los Países Bajos) de una adecuada cultura política y territorial. Pero queda, sin embargo, y es lo más importante, la frónesis de la política, o de los políticos, de la ética de la acción, de racionalidad de los valores, de la racionalidad sustantiva, como renovados "reyes filósofos", ahora gobernantes filósofos.

Es una cuestión a la que hemos empezado a aproximarnos, al tratar de responder a la cuestión de cómo poder situar mejor el desarrollo territorial en la agenda política a través de nuevas ventanas de oportunidad (Vera \& Farinós, 2015; Farinós, Vera \& Lloret, 2016). Allí concluíamos que actualmente, al menos en países como los nuestros (tomamos el conjunto de España como referencia), el territorio y su adecuada planificación y gestión no termina de formar parte de la agenda política, o lo hace de una manera oportunista y débil. Y ello porque las tres corrientes que debieran coincidir en el tiempo para que se generen las ventanas de oportunidad (Kingdom, 1995) no lo hacen: el reconocimiento social de un problema; la elaboración de una propuesta de solución o alternativa técnica para intervenir en el tema por parte de la administración; una serie de cambios políticos que deben acompañar a los anteriores procesos de forma necesaria para que se produzca una decisión pública. Respecto de lo primero, los responsables de gobierno, parlamentarios, altos cargos de las administraciones, el resto de actores y grupos externos a la gobernación, así como la propia ciudadanía, prestan atención en un momento determinado a diferentes temas. Por tanto, los resultados no animan a pensar que esta confluencia se pueda producir de forma espontánea o natural, 'per se', de acuerdo con las actuales condiciones. La recuperación del political will puede venir por presiones o motivaciones externas (vía conflicto ciudadano o castigo electoral - lo que en culturas clientelares como las mediterráneas no se produce con tanta claridad respecto del centro y norte de Europa) o como parte de una deseada nueva fronética política, que aquí se plantea como complemento fundamental a la fronética de la planificación.

\section{DE LA FRONÉTICA DE LA PLANIFICACIÓN A UNA NUEVA FRONÉTICA POLÍTICA EN LA PRÁCTICA; EL LARGO CAMINO. A MODO DE SÍNTESIS Y ALGUNA PROPUESTA PARA SEGUIR AVANZANDO}

A día de hoy no parece poder sustentarse la forzada división entre 'los que dicen y critican' (la academia y el episteme) de 'los que hacen' (la techne y los tomadores de decisiones. A lo largo de las páginas precedentes hemos querido demostrar que la planificación (que incluye diseño, implementación y evaluación) es un proceso cíclico en el que interactúan los diversos grupos de actores (expertos, técnicos, políticos y sociedad civil) de forma compleja e incluso iterativa en el marco de la posnormalidad. Respecto de las oportunidades de desarrollo y de la formulación de las políticas que las persigan, mucho se ha dicho sobre los sistemas de gobierno y de las estructuras de decisión, y de los estilos de planificación, pero poco sobre los procesos en que la gobernanza territorial se produce de facto y si es posible encontrar tipos y buenas marcas que permitan presentar recomendaciones. 
En este sentido, y fuera del ámbito nórdico o del noroeste europeo, considerado tradicionalmente como cuenca de innovación y buenas prácticas en esta materia, pueden destacarse como ejemplos de interés, además de la referida experiencia del Plan de Flandes bajo la dirección del Louis Albrechts, otras en sentido y contextos distintos como la de 'Thames Gateway' (Allmendinger \& Haughton, 2009), la de la nueva política territorial de Cataluña (Nel-lo, 2007; 2013) o la dilatada experiencia de la difícil práctica de la ordenación del territorio en España (Serrano, 2016). También se ha podido constatar que el diferente nivel de desarrollo y práctica de la planificación territorial entre las Comunidades Autónomas vendría a confirmar que esta actividad pública es dependiente, fundamentalmente, del conocimiento de la planificación y del reconocimiento de su utilidad potencial por parte de los políticos, así como de su voluntad para llevarla a cabo y lograr los objetivos explicitados en los instrumentos de planificación (Farinós, García \& Aldrey, 2016).

Para el caso español, un apurado conocimiento sobre el terreno de los departamentos responsables de la OT permite confirmar que la presencia de técnicos de alto rango cualificados y comprometidos que lideren el proceso en los departamentos de la administración regional (habitualmente en colaboración de expertos especialistas, algunos provenientes de la academia y/o el mundo de la consultoría profesional), también resulta un elemento clave en el comportamiento 'regional'. Los cambios legislativos, fruto de la propia evolución de la realidad social, económica y territorial no resultan de tipo incremental, provocándose entonces una especie de movimiento de corriente alterna (de 'stop and go', siendo que el 'go' que sigue al 'stop' suele caminar en sentido contrario al anterior) que obedece más a intereses y enfoques de cómo hacer uso del suelo y de los recursos territoriales que sobre cómo hacer planificación para, precisamente, poder hacer dicho uso y gestión.

En todos los casos referidos, en estos trabajos se demuestra que, aún uniendo episteme y techne, de forma innovadora y creativa, esto no asegura la planificación fronética, cuya pervivencia escapa a sus promotores y precisa de una frónesis de la política que intenta labrarse y abrirse paso, pero que en ningún caso se ha llegado a asegurar por completo.

A la hora de detallar ejemplos de buenas prácticas de frónesis política, éstas se refieren más bien a la acumulación y aplicación de los conocimientos sobre lo que funciona y lo que no (dónde, cómo y por qué), en diferentes situaciones y contextos, incluyendo un proceso continuo de aprendizaje, retroalimentación, reflexión y análisis. Una deseable opción sería poder diseñar un sistema que permitiera valorar los niveles de voluntad y compromiso político.

Para poder diferenciar buenas prácticas se propone el empleo de tres factores de referencia: marco legal e instrumental, las rutinas de gestión, y el marco político-cultura política. Su análisis, dentro de cada contexto particular en el cual se opere, nos aproxima al estudio de las tres corrientes que generan las ventanas de oportunidad de acuerdo con la teoría Kingdom (1995).

La naturaleza estratégica de la gobernanza territorial, y la necesidad de un profundo análisis de los juegos de negociación entre los actores involucrados, hace que 
todo proyecto de desarrollo territorial se caracterice por conflictos de intereses y de poder entre los actores públicos, privados y sociales involucrados. Por tanto, la gobernanza territorial depende en gran medida de la naturaleza de los conflictos en juego, de su carácter más o menos difuso y de la capacidad de los actores para negociar un compromiso aceptable. Goss (2001: 11) describe el concepto "local governance" como "una nueva y emergente forma de tomar decisiones en el nivel local que se desarrolla a través de diferentes relaciones, tanto entre agencias públicas como entre éstas y los ciudadanos". Esto es, haciendo especial hincapié en las rutinas de gestión se pretende mejorar las prácticas de gobernanza desde la frónesis política. Prácticas relativas a: rutinas organizativas que favorezcan la cooperación entre sectores y actores, la coordinación interadministrativa y la coherencia de las actuaciones, la capacidad de negociación, de co-producción de conocimiento que poder transferir (incluido el del territorio y de cómo emplear su potencial), de construir un medio eficaz de comunicación/difusión de la información entre actores y sectores, de generar confianza y compromiso a partir de unos objetivos comunes, etc.

En lo que se refiere al marco legal e instrumental, cabe centrarse en las herramientas, técnicas y métodos para la estructuración de la gobernanza territorial. Para ello, el marco legal se considera un factor relevante ya que éste establece las normas de derecho, las técnicas de gestión así como la ética en la cual se desarrolla la planificación. En este aspecto, en un reciente trabajo aún en edición (Farinós, Vera \& Lloret, 2016) se abordó esta cuestión mediante un Delphi a un grupo de expertos seleccionados a quienes se preguntó acerca de sí existía un marco legal, pero sobre todo reglamentario e instrumental, adecuado en la planificación territorial en España. Pudimos concluir que cuando se revisa la batería de instrumentos de ordenación territorial, y se desciende de la escala regional (planes, directrices, estrategias regionales) a las de detalle, nos encontramos ante el reto de trasladar las grandes recomendaciones a aplicaciones prácticas y concretas en las que se mantengan explícitos los juegos de poder y se permita gestionar el conflicto. Ante la diversidad de actores implicados, cabe una mejor asignación de roles y responsabilidades, cuya finalidad sea la de potenciar la cultura participativa, en un primer momento, pero, sobre todo, trabajar sobre la cultura del acuerdo. La cultura participativa y del acuerdo se enfrentaría al modelo clientelar al facilitar que los actores implicados puedan atribuir responsabilidades y ejercer los mecanismos de control designados.

Por su parte, el marco político nos remite a las técnicas y métodos para la elaboración de herramientas políticas. Para ello es necesario contar con la voluntad, compromiso y liderazgo político, así como con mecanismos que faciliten la rendición de cuentas. El compromiso y liderazgo político son determinantes a la hora de promover la planificación territorial como método de gobierno en sentido integral. La cultura política adopta especial importancia ya que ésta permite observar la relevancia y el reconocimiento de las ventajas de la OT como política pública. La falta de arraigo de la OT en la agenda política española, en ocasiones, viene acompañada por la falta de cultura participativa motivada por una baja concienciación social (Farinós, Vera \& Lloret, 2016). 
Se hace necesario trabajar en materia de concienciación de la ciudadanía para promover una adecuada cultura territorial que permita obtener mayores seguridades $y$ certezas sobre lo que se precisa en el territorio de cada cual. También, por tanto, para promover un adecuado sentido de pertenencia que facilite la apropiación del concepto de territorio por parte de la ciudadanía. Ello permitirá trabajar con otros mimbres a la hora de proponer nuevas formas y prácticas de planificación y formulación de políticas con impacto territorial.

Nuevas formas de promover inteligencia, observación y criterios claros de evaluación territorial (evitando las cajas negras con intereses ocultos detrás), en un renovado esfuerzo de dación de cuentas y transparencia, se nos muestran como un aspecto crucial para esta nueva ética práctica. Más aún en culturas clientelares y estilos de planificación muy pegados a los intereses particulares de los propietarios del suelo, donde la planificación no ha podido zafarse del lastre que supone: tanto la generación de plusvalías del suelo mediante su transformación (en economías poco diversificadas y muy dependientes de la explotación directa de los propios recursos físicos existentes - del que el suelo es uno de los principales- para beneficio de sectores como el inmobiliario, las infraestructuras y el turismo); como también el importante hecho de que estas plusvalías sean apropiables por parte del titular del suelo, lo que genera no ya conflictos por los posibles usos sino también en la prelación entre 'intereses', 'valores' y 'racionalidad' (en los movimientos especulativos los dos últimos se ven fácilmente sobrepasados por los primeros).

También la disponibilidad de recursos, económicos especialmente, para llevar a la práctica las propuestas de la planificación resulta un elemento crucial para poder hacer frente al frenesí especulador. De otra forma no será posible confrontar, para un juicio justo y racional (ajustado a criterio y valores), entre las ventajas de que la planificación exista sobre el hecho de que no. Este es precisamente el caso español, donde tal comparación resulta poco factible y, lo que es peor, útil, para demostrar su utilidad y bondades. De nuevo la cuestión de qué es lo más importante para el éxito de la planificación; si la estructura legal e institucional y las técnicas, o el entendimiento y lo compartido que ésta resulta entre los actores implicados y la población. ¿Qué importa más, el cómo o el qué? El hecho de que mucha de la planificación resulte inútil, al querer mantener las viejas formas (el cómo) frente a los nuevos problemas (el qué), apuntan a cuál es el cambio de orientación necesario.

La planificación maneja valores y significados, no solo evidencias. Por ejemplo, en materia de planificación estratégica la dimensión normativa viene de parte de la ética. En ese caso ¿cómo lograr un mejor entendimiento, complementariedad y coordinación entre planificación estratégica y la ordenación del territorio normativa? Ello reclama un análisis y entendimiento más depurado y ajustado del proceso de construcción relacional, especialmente social, frente a las normas políticas, muy por detrás, parece, de las verdaderas estructuras de poder. El planificador puede jugar un importante papel a la hora de estructurar el discurso y poder conseguir cambios institucionales (como se ha comentado para el caso de algunas Comunidades Autónomas españolas). ¿Cómo 
conseguir lograr las condiciones para que deje de ser para él una lucha continuada, como si de Sísifo se tratara?

Otra de las cuestiones de interés, en relación con este objetivo, es lograr una adecuada interacción y equilibrio entre las interpretaciones más amplias o comprehensivas de la planificación y acción política frente a las sectoriales y concretas. También entre el corto, medio y largo, y entre el plan y el proyecto, al objeto de procurar coherencia en la práctica política. El 'momento' es muy importante, y debe ser identificado y aprovechado. El planificador, técnico o experto puede incluso contribuir a crear las condiciones necesarias para que éste se produzca en la sociedad civil.

Otra línea que merecería atención especial es la de cómo poder tender mejores canales de comunicación entre expertos, técnicos y tomadores de decisiones por una parte (para que las iniciativas se mantengan sin que el técnico o experto deba consagrarse a la vigilancia), entre técnicos y decisores y sociedad civil por otra (de forma que el cambio de ciclo político no suponga el fin de una buena trayectoria en materia de política y agenda territorial), y entre todos ellos a la vez. En suma, cómo poder mejorar las condiciones culturales para la política territorial. Muchas personas tienen la información solo de oídas y, muchas veces, es la que les suministran de forma falsa e interesada grupos de presión con intereses contrarios a que exista planificación. Como hemos argumentado, la planificación tiene sentido si la gobernanza no queda reducida a una simple negociación de la diversidad de intereses presentes en el territorio, contrapuestos en la mayoría de ocasiones. Y la validez se ha definir como consenso sin fuerza, porque una norma no consensuada no tendrá recorrido, del mismo modo que los colectivos afectados pueden aceptar libremente las consecuencias de una norma controvertida y difícil.

Finalmente, cabe avanzar en las posibles fórmulas mediante las que poder promover una visión no disyuntiva excluyente entre gobierno-buen gobierno (normas formales) y gobernanza (no tan formales o establecidas - soft power) que asegure el mejor funcionamiento del sistema sin amenazar la democracia real y la necesaria función del Estado. El poder está en el centro de la planificación, y el que tiene el verdadero poder es capaz de determinar el significado de las palabras y el sentido de las propuestas. De ahí de la necesidad de garantizar unas reglas de gobernabilidad que arbitren sobre los distintos intereses para que puedan mantenerse en razonable co-habitación... a falta las más de las ocasiones de un único interés general o una única alternativa que claramente resulta la mejor.

Un ajustado conocimiento y entendimiento de las relaciones de poder, que faciliten su adecuado manejo y liderazgo, resulta imprescindible para promover cualquier tipo de cambio político. Y hay que reconocer que la planificación está llamada a provocar cambios, a ser transformativa, para hacer la sociedad no solo más resiliente sino también, y sobre todo, para que esta resiliencia (su distribución de cargas) sea más justa entre grupos de ciudadanos, entre instituciones y organismos (y entre ambos: ciudadanos y gobiernos), y entre territorios; ante cualquier eventual situación de crisis, necesidad y cambio, como a la que hoy en día nos enfrentamos. La planificación ha muerto, larga vida a la planificación. 


\section{AGRADECIMIENTOS}

Los autores agradecen los comentarios de las dos evaluaciones recibidas que han permitido ajustar y mejorar algunas de las partes del texto.

\section{BIBLIOGRAFIA}

Albet, A. \& Benach, N. (2010). Edward Soja. La perspectiva postmoderna de un geógrafo radical. Barcelona: Icaria.

Albrechts, L. (1999a). Planners as catalysts and initiators of change: the new structure plan for Flanders. European Planning Studies, 7 (5), 36-46.

Albrechts, L. (1999b). Planners and change. How do flemish planners on the shop floor cope with change? Sociedade e Territorio, 29, 36-46.

Albrechts, L. (2003a). Power and planning: towards an emancipatory planning approach. Environment \& Planning C, 21, 905-924.

Albrechts, L. (2003b). Planning versus Politics. Planning Theory, 2, 249-268.

Albrechts, L. (2016). Strategic planning as a catalyst for transformative practices. To be published In B. Haselsberger (Ed), Encounters in Planning Thought. 16 Autobiographical Essays from Key Thinkers in Planning. New York: Routledge.

Albrechts, L. \& Balducci, A. (2013). Practicing strategic planning: in search of critical features to explain the strategic character of plans. DisP, 49 (3), 16-27.

Allmendinger, P. \& Haughton, G. (2009). Soft spaces, fuzzy boundaries, and metagovernance: the new spatial planning in the Thames Gateway. Environment and Planning A, 41, 617-633.

American Planning Association (n.d.). What skills do planners need? Accedido a 9.02.16. Disponible en: https://www.planning.org/onthejob/skills. htm

Ansell, C. \& Gash, A. (2008). Collaborative governance in theory and practice. Journal of Public Administration Research and Theory, 18 (4), 543-571.

Benabent, M. (2010). El interés general en la filosofía política. Un concepto ético y normativo necesario para la planificación territorial. Boletín de la Asociación de Geógrafos Españoles, 53, 121-146.
Benabent, M. (2014). Introducción a la teoría de la planificación territorial. Sevilla: Universidad de Sevilla, Secretariado de publicaciones.

Bernstein, R. J. (1992). The new constellation: the ethicalpolitical horizons of modernity/postmodernity. Cambridge: Massachusetts, MIT Press.

Bourdieu, P. (1990). In other words: essays towards a reflexive sociology. Cambridge: Polity Press.

Brugué, Q. \& Vallès, J. M. (2005). Nuevos ayuntamientos, concejales diferentes. Del gobierno de las Instituciones al Gobierno de las Redes. Madrid: FEMP.

Chadwick, G. (1971). A systems view of planning: towards a theory of the urban and regional planning process. Oxford: Pergamon Press.

Chia, R. (1999). A "rhizomic" model of Organizational change and transformation: Perspective from a metaphysics of change. British Journal of Management, 10, 209-227.

Chia, R. (1995). From modern to postmodern organizational analysis. Organization Studies, 16, 579-604.

Comisión Europea-CE (2001). La Gobernanza euro-pea - un libro blanco, COM (2001) 428 final, DOCE C-287, de 12.10.2001. Disponible en: http://eur-lex.europa.eu/legal-content/ES/TXT/?uri= URISERV:110109 [consultado 9.02.16]

Dreyfus, H. \& Dreyfus, S. (1991). Sustaining non-rationalized practices: body-mind, power, and situational ethics. Interview conducted by Bent Flyvbjerg. Praxis International, 11, 93-113.

Faludi, A. (1985). The return of rationality. In M. Breheny \& A. Hoooper (Eds.) Rationality in Planning: Critical Essays on the Role of Rationality in Urban and Regional Planning (27-47). London: Pion.

Faludi, A. (1973). Planning Theory. Oxford: Pergamon.

Farinós, J. (2015a). Aménagement et gouvernabilité. Les liens entre rhétorique et pratiques. Une dernière chance pour le projet européen? L'Information géographique, 79 (1), 23-44. 
Farinós, J. (2015b). Administración y gestión del territorio como potencialidad para el buen gobierno. En Serrano, A. (ed.) Planificación y patrimonio territorial como instrumento para otro desarrollo. Ponencias presentadas al VII CIOT. Valencia, PUV-Fundicot (en prensa).

Farinós, J. (2014a). "Ciudadanos, poder, gobierno y democracia; una forma de relación inestable”. En J.L. Sahuquillo y J. Martín Cubas (eds.) La era de la \#Política2.0. Valencia, Ediciones Casas-AVAPOL, 24-34.

Farinós, J. (2014b). “Ordenación del Territorio desde la Geografía. De renovaciones conceptuales, retos, amenazas y espacios de oportunidad”. Polígonos. Revista de Geografía, 26, 17-58.

Farinós, J. (2009). "Bases, métodos e instrumentos para el desarrollo y la cohesión territoriales. Diagnóstico y propuestas para el debate y la acción”. En Farinós, J.; Romero, J. y Salom, J. (eds.) Cohesión e inteligencia territorial. Dinámicas y procesos para una mejor planificación en la toma de decisiones. Valencia, IIDL/PUV, Colección 'Desarrollo Territorial' $\mathrm{n}^{\circ} 7,17-62$.

Farinós, J. (ed. y coord.) (2007). Governance of Territorial and Urban Policies from EU to Local Level. Informe final del Proyecto ESPON 2.3.2, En línea: https://www.espon.eu/export/sites/default /Documents/Projects/ESPON2006Projects/ PolicyImpactProjects/Governance/fr-2.3.2 final_feb2007.pdf [consultado el 05/08/15].

Farinós, J. (2006). The governance of territorial and urban policies in Europe. European Territorial Research in Progress, Conference proceedings of the $1^{\text {st }}$ ESPON Scientific Conference. Malmö, ESPON PROGRAM, 101-113.

Farinós, J., García, Ma J. \& Aldrey, J. A. (2016). “Desarrollo legislativo y planificador en materia territorial y urbanística a nivel español"; en Farinós, J. (ed. y coord.) Cómo hacer del territorio cuestión politica de Estado / Achieving Territory Becomes Matter of State Importance / Come faire du Territoire une question politique d'État. Valencia, Tirant Lo Blanch. (En edición).

Farinós, J.; Vera, O. \& Lloret, P. (2016). Nueva cultura política y territorial; relaciones entre política y territorio. O de cómo situar el territorio en la agenda política. En J. Farinós (Ed. y coord.) op.cit. (en edición).

Farinós, J. \& Ferrão, J. (2015). Gobernanza. En López
Trigal, L. (coord.) Diccionario de Geografía Aplicada y Profesonal. Terminologia de analisis, planificacion y gestion del territorio. León: Universidad de León.

Flyvbjerg, B. (1998a). Habermas and Foucault: Thinkers for Civil Society? The British Journal of Sociology, 49 (2), 210-233.

Flyvbjerg, B. (1998b). Rationality and power: democracy in practice. Chicago: The University of Chicago Press.

Flyvbjerg, B. (2001). Making social science matter: why social inquiry fails and how it can succeed again. Cambridge: Cambridge University Press.

Flyvbjerg, B. (2002). Bringing power to planning research: one researcher's praxis story. Journal of Planning Education and Research 21 (4), 353-366.

Flyvbjerg, B. (2004). Phronetic Planning Research: Theoretical and Methodological Reflections. Planning Theory \& Practice, 5 (3), 283-306.

Flyvbjerg, B., Landman, T. \& Schram, S. (2012). Introduction: new directions in social science. In B. Flyvbjerg, T. Landman \& S. Schram, (Eds.), Real Social Science: Applied Phronesis (1-14). Cambridge: Cambridge University Press.

Foucault, M. (1980). The History of Sexuality. Vol. 1. NewYork: Vintage.

Foucault, M. (1982). The subject and power. In H. P. Dreyfus \& P. Rabinow (Eds.), Michel Foucault: Beyond Structuralism and Hermeneutics (214-232). Brighton, Harvester Press.

Foucault, M. (1984a). Le Retour de la morale. Les Nouvelles. 28 June. 5 July 1984: 36-41.

Foucault, M. (1984b). Space, knowledge, and power. Interview with Paul Rabinow. In P. Rabinow (Ed.), The Foucault Reader (239-256). New York: Pantheon.

Foucault, M. (1988). The ethic of care for the self as a practice of freedom. In J. Bernauer \& D. Rasmussen (Eds.), The Final Foucault (112-131). Cambridge: Massachusetts, MIT Press.

Funtowicz, S. O. \& Ravetz, J. R. (1991). A New Scientific Methodology for Global Environmental Issues. In R. Costanza (Ed.), Ecological economics: the science and management of sustainability (137-152). New York: Columbia University Press.

Funtowicz, S.O. \& Ravetz, J. R. (1993). Science for the Post-Normal Age. Futures, 25/7, 739-755.

Funtowicz, S. O. \& Ravetz, J. R. (2000). La ciencia posnormal: ciencia con la gente. Barcelona: Icaria Editorial. 
Galland, D. (2012). Understanding the reorientations and roles of spatial planning: the case of national planning policy in Denmark. European Planning Studies, 20 (8), 1359-1392.

Giddens, A. (1984). The constitution of society: outline of the theory of structuration. Cambridge: Polity Press.

Goss, S. (2001). Making local governance work. Londres: Palgrave.

Habermas, J. (1985). Questions and counterquestions. In R. J. Bernstein (Ed.), Habermas and Modernity (198). Cambridge: Massachusetts, MIT Press.

Habermas, J. (1987). The philosophical discourse of modernity. Cambridge: Massachusetts, MIT Press.

Habermas, J. (1990). Moral consciousness and communicative action. Cambridge: Massachusetts, MIT Press.

Habermas, J. (1993). Justification and application: remarks on discourse ethics. Cambridge: Massachusetts, MIT Press.

Hirschman, A. O. (1994). Social conflicts as pillars of democratic market society. Political Theory, 22, 203-218.

Jessop, B. (2003). Governance and metagovernance: on reflexivity, requisite variety, and requisite irony. UK, Lancaster: Department of Sociology, Lancaster University. Accedido a 9.02.16. Disponible en: http://www.lancaster.ac.uk/ sociology/research/publications/papers/jessopgovernance-and-metagovernance.pdf

Keane, J. (1988). Democracy and civil society: on the predicaments of european socialism the prospects for democracy and the problem of controlling social and political power. Londres: Verso.

Kettner, M. (1993). Scientific knowledge, discourse ethics and consensus formation in the public domain. In E. R. Winkler \& J.R. Coombs (Eds.), Applied ethics: a reader. Oxford: Basil Blackwell.

Leroux, I. (2006). Gouvernance territoriale et jeux de négociation. Négociations, 2, 83-98. http://www. cairn.info/resume.php?ID ARTICLE=NEG $\underline{00698}$

McLoughlin, J. B. (1969). Urban and regional planning: a systems approach. London: Faber and Faber.

Maquiavelo, N. (1996). Discursos sobre la primera década de tito livio. Madrid: Alianza Editorial.

March, J.G. \& Simon, H. A. (1958). Organizations. New York: John Wiley \& Sons, Inc.
Massey, D. B., \& Allen, J. (Eds.) (1984). Geography matters! A reader. Cambridge: Cambridge University Press-The Open University.

Moore, M.L. et al. (2014). Studying the complexity of change: toward an analytical framework for understanding deliberate social-ecological transformations. Ecology and Society, 19 (4), 54. http:// www.ecologyandsociety.org/vol19/iss4/art54

Nelllo, O. (2007). La nueva política territorial en Cataluña (2003-2006). En J. Farinós, J. Romero (Eds.), Territorialidad y buen gobierno para el desarrollo sostenible. Nuevos principios y nueva políticas en el espacio europeo. Valencia: IIDL/PUV, Colección 'Desarrollo Territorial' no 2, 199-236.

Nel.lo, O. (2012). Ordenar el Territorio. La experiencia de Barcelona y Cataluña. Valencia: Tirant-Humanidades. Colección Crónica.

Olsson, P., Folke, C. \& Hahn, T. (2004). Social-ecological transformation for ecosystem management: the development of adaptive co-management of a wetland landscape in southern Sweden. Ecology and Society 9(4). 2. http://www.ecologyandsociety.org/vol9/iss4/art2/ [consultado 9.02.16].

Olsson, P. et al. (2006). Shooting the rapids: navigating transitions to adaptive governance of social-ecological systems. Ecology and Society 11(1), 18. Acedido a 9.02.16. Disponible en: http://www. ecologyandsociety.org/vol11/iss1/art18.

Planning Institute Australia (n.d.). What is planning? Acedido a 9.02.16. Disponible en: https://www. planning.org.au/becomeaplanner

Prezioso, M. (2008). The territorial dimension of a competitive governance in sustainability. Boletín de la Asociación de Geógrafos Españoles, 46, 163-179.

Putnam, R. D., Leonardi, R. \& Nanetti, R.Y. (1993). Making democracy work: civic traditions in modern Italy. Princeton: NJ, Princeton University Press.

Serrano, A. (2016). La Ordenación del Territorio en España: pasado, presente y ¿futuro? Una visión desde experiencias de gestión propias. In J. Farinós (Ed. y coord.) op.cit. (en edición).

Simon, H.A. (1946). Administrative behavior. A study of decision-making processes in administrative organization. New York: The Free Press.

Subirats, J. (en edición). La política entre los argumentos de la razón y las exigencias de la democracia. Acerca de las decisiones públicas. In J. Farinós (Ed. y coord.) De cómo hacer del territorio cuestión política de Estado. Elementos para una coor- 
dinación de las políticas de ordenación del territorio. Valencia: Tirant Lo Blanch.

Vera, O. \& Farinós, J. (2015). La atención prestada al territorio en las políticas públicas: apuntes a partir de la primera fase de un Delphi. XXIV Congreso de la AGE. Análisis espacial y representación geo- gráfica: innovación y aplicación. Zaragoza, del 28-30 de octubre de 2015, 11 págs.

Vickers, G. (1995). The art of judgement: a study of policy makingk. London: Sage.

Weber, M. (1978). Economy and Society. Berkeley: University of California.

i Este trabajo ha sido realizado en el marco del proyecto de investigación CS02012-36960 «Del gobierno a la gobernanza y gobernabilidad efectiva del territorio: guías para un nuevo desarrollo territorial», Plan Nacional de I+D+i 2008-2011, Subprograma de Proyectos de Investigación Fundamental del Ministerio de Economía y Competitividad, cofinanciado por el FEDER.

ii Es el mismo razonamiento que utiliza Faludi (1985) para hacer de la racionalidad prueba metodológica en la planificación, mediante la que una decisión únicamente puede ser aceptada si se demuestra que supera a sus alternativas.

iii "Maquiavelo pretende que, en un mundo tan malo y corrupto, no es posible ser completamente bueno sin exponerse a perecer. Por mi parte afirmo que, a fin de no perecer, hay que ser tanto precavido como virtuoso" (Federico II de Prusia, 1740: El anti-Maquiavelo, cap. XV).

iv El proceso de elecciones del candidato republicano a la presidencia de los EE.UU., con la figura de Donald Trump, resulta ejemplo bien ilustrativo.

v Sobre la idea y concepto de interés general en planificación puede verse Benabent, 2010.

vi Esto nos acerca a la Teoría de los Sistemas Complejos, en tanto se fija más en los flujos y procesos que en los elementos y estructura del sistema; y a un entendimiento de las nuevas formas de gobernanza como proceso en lugar de como estado o precondición.

vii Los conflictos y su gestión conectan con otros planteamientos y teorías como las de la innovación social, gestión de la transición y los movimientos sociales, y éstas a su vez con los estudios sobre resiliencia y también con los sistemas socio-ecológicos (Olson et al., 2004 y 2006; citados en Moore et al. 2014).

viii Así lo entendimos en (Farinós, 2007), donde incorporamos los estudios de caso como metodología fundamental del proyecto, $y$ tratamos de justificarlo por el entonces en el marco del Programa ESPON I, pasando a formar parte de muchos proyectos en las sucesivas fases del programa (II y la actual III).

ix Los antecedentes de este interés por lo particular y los estudios de caso (específicos e indicativos), frente al criterio de centrarse en las 'grandes preguntas' y los 'problemas importantes', tiene sus antecedentes en la fenomenología, y conecta con el posmodernismo, los estudios de localidades y la importancia del espacio en la teoría social a la hora para explicar los resultados de las relaciones de producción y del poder (tanto o más que la historia, según el propio Soja, vid. Albet \& Benach, 2010).

$x$ Concepto que se ha banalizado y ridiculizado, llegando a resultar incluso jocoso ('el menos común de todos los sentidos'), pero que cabe reivindicar como "el arte del juicio" (Vickers, 1995), consistente en optar por las decisiones a tomar desde una perspectiva de actor social virtuoso (en ese sentido se manifestaba Alejandro II de Prusia en su réplica al nihilismo que interpretaba en Maquiavelo, como se ha referido). A falta de una palabra moderna satisfactoria que recoja la idea, en la bibliografía se recurre al original aristotélico de phronesis (frónesis).

xi A la hora de resolver problemas, y en función del nivel de incertidumbre y posible conflicto, hay que escoger entre tres tipos de estrategias posibles: la ciencia aplicada, la consultoría profesional y la ciencia posnormal. La consultoría. presenta elementos comunes con la ciencia aplicada (tiempo y recursos limitados y existencia de intereses contradictorios), sin embargo resultan claramente diferenciadas. Los resultados de la ciencia aplicada son reproducibles y predictibles, mientras que la consultoría trabaja en situaciones únicas que requieren de juicios personales y, por tanto, de destrezas de alto nivel para manejar la incertidumbre (Funtowicz \& Ravetz, 2000: 42).

xii Combinando la interpretación de autores como Foucault, Nietzsche o Weber, el análisis del poder es guiado por una concepción del mismo caracterizada por: 1) el poder es productivo y positivo, y no sólo restrictivo o negativo; 2) se ve como una red densa de las relaciones omnipresentes, y no sólo localizado en "centros", organizaciones e instituciones, o como una entidad que uno puede "poseer"; 3) es visto como algo muy dinámico; el poder no es simplemente algo que uno se apropia, es re-apropiable, un movimiento de ida y vuelta constante dentro de las relaciones de fuerza, tácticas y estrategias existentes (aunque justamente los intentos apropiación y exclusividad no han dejado de producirse, con sus efectos y consiguientes reacciones, y revoluciones; 4) conocimiento y poder, verdad y poder, racionalidad y poder, son analíticamente inseparables uno del otro, el poder produce conocimiento y el conocimiento es poder; 5) La pregunta crucial es cómo se ejerce el poder, y no sólo quién tiene el poder, el foco está en proceso y no sólo en la estructura (lo que abre el campo a nuevos conceptos como el de gobernanza y nuevos enfoques como el de la teoría de los sistemas complejos, la ciencia posnormal y la transdisciplinariedad); 6) el poder y su funcionamiento puede, y debe, estudiarse de forma contextualizada, plana y empírica (en forma de "pequeñas preguntas", a través de estudios de caso y análisis cualitativos y en profundidad; métodos cuantitativos e inductivos frente al neopositivismo clásico), como punto de partida de lo que (Foucault, 1982: 217; en Flyvbjerg, 2004) llama "grandes preguntas". 